\title{
Monoclonal antibody-based biosensor for point-of-care detection of type III secretion system expressing pathogens
}

Yaron Hillman ${ }^{1 \ddagger} \mid$ Jenia Gershberg $^{2 \ddagger} \mid$ Dan Lustiger ${ }^{1 \ddagger} \mid$ Dan Even $^{1} \mid$ Dor Braverman ${ }^{2} \mid$ Yael Dror $^{1} \mid$ Idan Ashur | Sefi Vernick ${ }^{3}$ Neta Sal-Man ${ }^{2^{*}}$ | Yariv Wine ${ }^{1^{*}}$

${ }^{1}$ The Shmunis School of Biomedicine and Cancer Research, George S. Wise Faculty of Life Sciences, Green building, Tel-Aviv University, Tel Aviv, 6997801, Israel

${ }^{2}$ Department of Microbiology, Immunology and Genetics, Faculty of Health Sciences, Ben-Gurion University of the Negev, P.O.Box 653, Beer Sheva 8410501, Israel

${ }^{3}$ Institute of Agricultural Engineering, Agricultural Research Organization -Volcani Center, 68 Hamaccabim Rd, Rishon Lezion, 5025001, Israel

Corresponding authors: Neta Sal-Man, email: salmanne@bgu.ac.il

Yariv Wine, email: yarivwine@tauex.tau.ac.il

Table of contents

\begin{tabular}{|l|l|l|}
\hline Methods & & \\
\hline & Bacterial strains & S2 \\
\hline & Expression and purification of recombinant EspB & S2 \\
\hline & Phage panning, mAb-EspB-B7 expression and purification & S2 \\
\hline & Enzyme-linked immunosorbent assay (ELISA) & S2 \\
\hline & Surface plasmon resonance (SPR) & S3 \\
\hline & $\begin{array}{l}\text { In vitro type 3 secretion assay } \\
\text { Immunoblotting }\end{array}$ & $\mathrm{S} 3$ \\
\hline & $\begin{array}{l}\text { Flow cytometry } \\
\text { chromatography }\end{array}$ & $\mathrm{S} 3$ \\
\hline & $\begin{array}{l}\text { Epitope mapping using peptide array } \\
\text { Effector translocation activity }\end{array}$ \\
\hline
\end{tabular}




\begin{tabular}{|l|l|l|}
\hline & Electrochemical biosensor fabrication & S4 \\
\hline & Biosensor measurements & S4 \\
\hline & Electrochemical Impedance Spectroscopy measurements & S5 \\
\hline & The equivalent circuit & S5 \\
\hline Figures & Figure S1. mAb-EspB-B7 is thermally stable. & S6 \\
\hline & Figure S2. mAb-EspB-B7 binding to EspB peptides. & S7 \\
\hline & $\begin{array}{l}\text { Figure S3. mAb-EspB-B7 sequence alignment with EspB homologs } \\
\text { in other T3SS-expressing bacteria }\end{array}$ & S8 \\
\hline & $\begin{array}{l}\text { Figure S4. mAb-EspB-B7 does not inhibit EPEC translocation } \\
\text { activity into HeLa cells. }\end{array}$ & S9 \\
\hline References & References & S9 \\
\hline
\end{tabular}

\section{METHODS}

\section{Bacterial strains}

Wild-type (WT) EPEC O127:H6 strain E2348/69 [streptomycin-resistant] and EPEC null mutants ( $\Delta e s c N, \Delta e s p B, \Delta e s p D)$ were used to purify EspB, to evaluate mAb-EspB-B7 binding, and to assess T3SS and translocation activities ${ }^{1-3}$. WT and T3SSmutant strains of Citrobacter rodentium DBS100 ${ }^{4}$, enterohemorrhagic E. coli (EHEC) ${ }^{5}$, and Salmonella enterica serovar Typhimurium ${ }^{6}$ were used to assess antibody specificity. Antibiotics were used at the following concentrations: streptomycin (50 $\mu \mathrm{g} / \mathrm{mL})$, ampicillin $(100 \mu \mathrm{g} / \mathrm{mL})$, chloramphenicol $(30 \mu \mathrm{g} / \mathrm{mL})$, and nalidixic acid $(50 \mu \mathrm{g} / \mathrm{mL})$.

Expression and purification of recombinant EspB

EPEC O127:H6 strain E2348/69 deleted for the espB gene $(\triangle e s p B)^{3}$ was transformed with a bacterial expression vector encoding Histagged EspB (EspB-His) and grown overnight in Luria-Bertani (LB) broth supplemented with the appropriate antibiotics. The following steps of the expression and purification of $\mathrm{EspB}$ are described in details in the supporting information.

The overnight culture was diluted 1:50 and grown for $3 \mathrm{hr}$ under T3SS-inducing conditions (pre-heated Dulbecco's modified Eagle's medium [DMEM] in a tissue culture incubator with 5\% CO2, statically). These conditions induce the secretion of EspB into the extracellular environment. Next, $0.5 \mathrm{mM}$ isopropyl- $\beta$-d-thiogalactopyranoside (IPTG) was added, and the culture was grown for an additional $4 \mathrm{hr}$. The culture was centrifuged for $30 \mathrm{~min}$ at $12000 \times \mathrm{g}$, and the supernatant containing the secreted EspB-His was collected and supplemented with protease inhibitor cocktail of $200 \mathrm{mM}$ phenylmethylsulfonyl fluoride (PMSF) and $1 \mu \mathrm{M}$ benzamidine. The supernatant was then loaded on a His-Trap HP 1-mL column (GE Healthcare), washed with 50 $\mathrm{mM}$ imidazole, and eluted with $500 \mathrm{mM}$ imidazole, according to the manufacturer's protocol. The elution fractions were analyzed by SDS-PAGE and Coomassie staining to identify the fractions that contain the purified protein. The recovered protein was further purified by gel filtration chromatography using a Superose 12 10/300 GL column (GE Healthcare). The peak fractions were collected, frozen in liquid nitrogen and stored at $-80^{\circ} \mathrm{C}$.

Phage panning, mAb-EspB-B7 expression and purification

$\mathrm{mAb}-\mathrm{EspB}-\mathrm{B} 7 \mathrm{~V}_{\mathrm{H}}$ and $\mathrm{V}_{\mathrm{L}}$ were cloned in mammalian expression vectors (pcDNA3.4H and pcDNA3.4L encoding the IgG1 heavy and lambda light chain constant regions) by Gibson cloning ${ }^{7}$. The cloned vectors were transformed into E. coli competent 
cells (XL-1 blue) and were purified using plasmid purification kit (Invitrogen). The vectors were co-transfected into Expi293 expression system (Gibco) according to the manufacturer's instructions. Transfected Expi293 cells were harvested by centrifugation at $2000 \times \mathrm{g}$ for $10 \mathrm{~min}$ at $4{ }^{\circ} \mathrm{C}$ and conditioned medium was applied to MabSelect affinity column (GE Healthcare) according to the manufacturer's instructions.

Enzyme-linked immunosorbent assay (ELISA)

For all ELISA experiments, 96-well ELISA plates were coated with $5 \mu \mathrm{g} / \mathrm{mL}$ of target antigen in PBS and incubated overnight at $4{ }^{\circ} \mathrm{C}$. Blocking, washing and detection steps were carried out as described previously ${ }^{8}$. Beefily, EspB coated 96-well plates were blocked with $300 \mu \mathrm{L} /$ well of $3 \%\left[\mathrm{w} / \mathrm{v}\right.$ ] skim milk in PBS for $1 \mathrm{hr}$ at $37^{\circ} \mathrm{C}$ and washed with PBS. mAb-EspB-B7 in blocking solution was added to the first line of the plate and serially diluted throughout the plate. The plate was incubated for $1 \mathrm{hr}$ at room temperature, washed, and incubated with goat anti-human H+L HRP-conjugated secondary antibody in 0.05\% PBST (Jackson ImmunoResearch) for $1 \mathrm{hr}$ at room temperature. Plates were then washed and signal was developed using 3,3',5,5'tetramethylbenzidine (TMB). The reactions were quenched by $1 \mathrm{M} \mathrm{H}_{2} \mathrm{SO}_{4}$ and absorbance was measured at optical density (OD) of $450 \mathrm{~nm}$ (Epoch, BioTek). ELISA assays to test mAb-EspB-B7 binding in various conditions were carried out using similar protocol as described above with the following modifications: (i) for binding under various $\mathrm{pH}$ conditions, $\mathrm{mAb}$-EspBB7 was incubated in $0.1 \mathrm{M}$ citric acid buffer $\mathrm{pH} 7.4,7.0,6.6,5.6$, and 4.6 during the binding step; (ii) for binding at various salt concentrations, mAb-EspB-B7 was incubated in $45.6 \mathrm{nM}, 68.5 \mathrm{nM}, 137 \mathrm{nM}, 274 \mathrm{nM}$, and $411 \mathrm{nM} \mathrm{NaCl}$; and (iii) for assessment of the serum effect on mAb-EspB-B7 binding, the antibody was incubated in 10\% goat or horse serum with $1 \%$ Tween 20 and $1 \%$ human serum during the binding step. Competitive ELISA with peptides was carried out as follows: A 96-well ELISA plate (I) and a 96-well inert Bradford plate (II) were used for each of the peptides examined. The respective scrambled peptides (carrying the same amino acid compositions in a scrambled order), full-length EspB and peptide \#78 were used as positive and negative controls, respectively. Plate I was coated with $3 \mu \mathrm{g} / \mathrm{ml} \mathrm{EspB} \mathrm{or} \mathrm{PBS} \mathrm{and} \mathrm{incubated} \mathrm{overnight} \mathrm{at} 4^{\circ} \mathrm{C}$. Blocking of plate I was performed as described above. $\mathrm{mAb}$-EspB-B7 $(15 \mathrm{nM})$ was pre-incubated with serially diluted concentrations of peptides, starting at $15 \mu \mathrm{g} / \mathrm{mL}$ for $1 \mathrm{hr}$ at room temperature, transferred to plate $\mathrm{I}$, and incubated for $1 \mathrm{hr}$ at room temperature. The remaining steps were performed as described above for regular ELISA.

Surface plasmon resonance (SPR)

Association and dissociation of the EspB-mAb-EspB-B7 complex was monitored by SPR with a Biacore 200 apparatus (GE Healthcare Life Sciences) with EspB immobilized on a CM5 chip (GE Healthcare Life Sciences). SPR experiments were conducted according to the manufacturer protocols. Immobilization of EspB on CM5 chip was carried out by amine coupling chemistry using the following protocol at a flow rate of $10 \mu \mathrm{L} / \mathrm{min}$ and with $20 \mathrm{mM}$ phosphate buffer with $0.15 \mathrm{M} \mathrm{NaCl}$, and $0.005 \%$ Tween 20 at pH 5.91 as a running buffer. The chip was first activated by injecting a freshly prepared mixture of $50 \mathrm{mM}$ $\mathrm{N}$-hydroxysuccinimide and $195 \mathrm{mM}$ 1-ethyl-3-(3-dimethylaminopropyl) carbodiimide for $7.5 \mathrm{~min}$, then EspB $(2.5 \mu \mathrm{g} / \mathrm{mL}$ in PBS buffer containing surfactant P20, $10 \mathrm{mM}$ HEPES $\mathrm{pH} 7.4,150 \mathrm{mM} \mathrm{NaCl}$, and $3 \mathrm{mM}$ EDTA) was injected for 5 min to reach 120 resonance units (RU), and finally the remaining activated carboxylic groups were blocked by injecting $1 \mathrm{M}$ ethanolamine hydrochloride, $\mathrm{pH}$ 8.6, for $5 \mathrm{~min}$. The association of mAb-EspB-B7 with EspB was monitored by injecting different concentrations of $\mathrm{mAb}$-EspB-B7 for $4 \mathrm{~min}$ at a flow rate of $30 \mu \mathrm{L} / \mathrm{min}$, and the dissociation was monitored at the end of the antibody injection. To regenerate the chip, $5 \mathrm{mM} \mathrm{NaOH}$ solution was used. Data analysis was carried out by fitting the sensorgrams to the steady state model (T200 evaluation software).

In vitro type 3 secretion assay

EPEC strains were grown overnight in LB supplemented with the appropriate antibiotics in a shaker at $37^{\circ} \mathrm{C}$. The cultures were diluted 1:40 into pre-heated DMEM (Biological Industries) and grown statically for $6 \mathrm{hr}$ in a tissue culture incubator (with $5 \% \mathrm{CO} 2)$, to an OD of 0.7 at $600 \mathrm{~nm}$ (OD600). These conditions simulate host environment and induce T3SS expression. The cultures were then centrifuged at $20000 \times g$ for $5 \mathrm{~min}$ to separate the bacterial pellets from the supernatants; the pellets were dissolved in SDS-PAGE sample buffer, and the supernatants were collected and filtered through a $0.22-\mu \mathrm{m}$ filter (Millipore). The supernatants were then precipitated with $10 \%(\mathrm{v} / \mathrm{v})$ trichloroacetic acid (TCA) overnight at $4^{\circ} \mathrm{C}$ to concentrate proteins 
secreted into the culture medium. The volume of the supernatants was normalized to the bacterial cultures at OD600 to ensure equal loading of the samples. The samples were then centrifuged at $18000 \times \mathrm{g}$ for $30 \mathrm{~min}$ at $4^{\circ} \mathrm{C}$, the precipitates of the secreted proteins were dissolved in SDS-PAGE sample buffer, and the residual TCA was neutralized with saturated Tris. The T3SS activity of $C$. rodentium was determined similarly to that described for EPEC. For EHEC, we cultured double the amount of EPEC ( $8 \mathrm{~mL}$ cultures instead of $4 \mathrm{~mL}$ ) due to lower amounts of secreted proteins of EHEC relative to EPEC.

\section{Immunoblotting}

Samples were subjected to SDS-PAGE and transferred to nitrocellulose membranes (pore size: $0.45 \mu \mathrm{m}, \mathrm{Bio}-\mathrm{Rad}$ ) or polyvinylidene difluoride (PVDF, Mercury, Millipore). The blots were blocked for $1 \mathrm{hr}$ with $5 \%$ (w/v) skim milk-PBST (0.1\% Tween in phosphate-buffered saline), incubated with the primary antibody (diluted in 5\% skim milk-PBST for $1 \mathrm{hr}$ at room temperature or overnight at $4{ }^{\circ} \mathrm{C}$ ), washed, and then incubated with the secondary antibody (diluted in 5\% skim milk-PBST, for 1 $\mathrm{hr}$ at room temperature). Chemi-luminescence was detected with EZ-ECL reagents (Biological Industries). The following primary antibodies were used: mAb-EspB-B7, diluted 1:1000; mouse anti-EspB (a gift from Prof. Finlay, University of British Columbia), diluted 1:1000; mouse anti-His (Pierce), diluted 1:2000; mouse anti-JNK (BD Pharmingen), diluted 1:1000 in TBS; and mouse anti-actin (MPBio), diluted 1:10,000. The following secondary antibodies were used: horseradish peroxidaseconjugated (HRP)-goat anti-mouse (Abcam Inc.) and HRP-conjugated goat anti-human (Abcam Inc) antibodies.

\section{Flow cytometry}

EPEC bacteria were grown overnight in LB with the appropriate antibiotics. The cultures were diluted 1:40 and grown under T3SS-inducing conditions for $3 \mathrm{hr}$. Thereafter, $1 \times 10^{7}$ bacteria were plated in a 96-U shape well plate and centrifuged at $800 \times g$ for $5 \mathrm{~min}$, and the supernatants were removed. Bacteria were incubated with primary antibody (mAb-EspB-B7, 1:100) for $1 \mathrm{hr}$ at room temperature, washed with PBS, and stained using Alexa Fluor 488 goat anti-human IgG secondary antibody (Jackson ImmunoResearch) for $30 \mathrm{~min}$. Samples were washed and resuspended in PBS for analysis. Flow cytometry analysis was performed on Gallios (Beckman Coulter) equipped with $488 \mathrm{~nm}, 405 \mathrm{~nm}$ and $638 \mathrm{~nm}$ lasers and a switchable $561 \mathrm{~nm}$ laser. Data analysis was performed with Kaluza software (Beckman Coulter).

Co-elution of EspB and EspD35-His by nickel affinity chromatography

EPEC $\triangle e s p D$ in the presence or the absence of an EspD- ${ }^{35} \mathrm{His}$ expression vector, was grown under T3SS-inducing conditions for $7 \mathrm{hr}$ ( $0.5 \mathrm{mM}$ IPTG was added after $3 \mathrm{hr}$ to induce protein expression). To evaluate the ability of mAb-EspB-B7 to inhibit the interaction between EspB and EspD, 100 or $200 \mathrm{nM}$ of mAb-EspB-B7 were added to EPEC $\triangle$ espD expressing EspD-35His sample. The supernatants, containing secreted EspD- ${ }^{35} \mathrm{His}$ and EspB, were collected by centrifugation $(20000 \times g$ for $5 \mathrm{~min})$ and were passed through a 0.45 - $\mu \mathrm{m}$-pore-size filter. Protease inhibitor solution was added to the samples (200 mM PMSF and $1 \mu \mathrm{M}$ benzamidine), and they were incubated with Ni-NTA resin while being rotated overnight at $4^{\circ} \mathrm{C}$. The samples were then loaded on gravity columns, and the flow-through was collected. The columns were washed three times with $5 \mathrm{~mL}$ of washing buffer (30 $\mathrm{mM}$ phosphate buffer $\mathrm{pH} 7.5,500 \mathrm{mM} \mathrm{NaCl}, 50 \mathrm{mM}$ imidazole), and proteins were eluted using elution buffer ( $30 \mathrm{mM}$ phosphate buffer $\mathrm{pH} 7.5,500 \mathrm{mM} \mathrm{NaCl}, 500 \mathrm{mM}$ imidazole). Equal volumes of the supernatant and the eluate samples were precipitated with $10 \%(\mathrm{v} / \mathrm{v}) \mathrm{TCA}$ for $1 \mathrm{hr}$ at $4^{\circ} \mathrm{C}$, centrifuged $\left(30 \mathrm{~min}, 16000 \times \mathrm{g}, 4^{\circ} \mathrm{C}\right)$, air dried, and dissolved in SDS-PAGE sample buffer. Supernatants and eluted samples were analyzed by SDS-PAGE and western blotting using mouse anti-His and mouse anti-EspB antibodies, to avoid detection of the human mAB-EspB-B7 antibody.

Epitope mapping using peptide array

Peptide microarrays of 15-residues cyclic peptides, derived from the EspB sequence and containing an overlap of 11 residues, were obtained from JPT Peptide Technologies GmbH. Peptide array analysis was carried out according to the manufacturer protocols. For further details see supporting information.Each microarray included three identical subarrays as technical triplicates. Full-length EspB protein was spotted on the array and used as a positive control, while bovine serum albumin (BSA) served as a negative control. The binding of $\mathrm{mAb}-\mathrm{EspB}-\mathrm{B} 7$ to the peptide array was carried out according to the manufacturer's instructions (www.jpt.com), with minor modifications. Briefly, $20 \mu \mathrm{g} / \mathrm{mL}$ mAb-EspB-B7 (0.1\% TBST v/v) were incubated on 
the peptide microarray for $2 \mathrm{hr}$ at room temperature. The peptide microarray slides were then washed (five times with TBST), incubated with Alexa Fluor 647-affinipure mouse anti-human IgG (Jackson ImmunoResearch) for 45 min at room temperature, washed (five times with TBST and then five times with doubly distilled H2O), and dried. Fluorescence was detected with a GenePix 4000B scanner (Molecular Devices) at a resolution of $10 \mu \mathrm{m}$ pixel size and analyzed by the Genepix Pro 6.0 analysis software (Molecular Devices). Signals were normalized and plotted to reflect the relative intensities of the fluorescence signals.

\section{Effector translocation activity}

HeLa cells $\left(8 \times 10^{5}\right.$ cells per well $)$ were infected for $3 \mathrm{hr}$ with EPEC strains that were pre-induced for $3 \mathrm{hr}$ for T3SS activity (pre-heated DMEM, statically, in a $\mathrm{CO}_{2}$ tissue culture incubator). Cells were then washed with PBS, collected, and lysed with RIPA buffer. Samples were centrifuged at $18000 \times \mathrm{g}$ for $5 \mathrm{~min}$ to remove non-lysed cells, and supernatants were collected, mixed with SDS-PAGE sample buffer, and subjected to western blot analysis with anti-JNK and anti-actin antibodies (loading control). Uninfected samples and the $\triangle e s c N$ mutant strain-infected samples were used as negative controls. To evaluate the ability of $\mathrm{mAb}$ EspB-B7 to inhibit EPEC translocation activity, $400 \mathrm{nM}$ of mAb-EspB-B7 were added to a sample infected with WT EPEC.

\section{Electrochemical biosensor fabrication}

Electrochemical biochips were designed as electrochemical cells with a three-electrode configuration (working, counter and reference electrodes) and microfabricated on a p-doped $\mathrm{Si} / \mathrm{SiO}_{2}$ substrate (with $285 \mathrm{~nm}$ thermally grown oxide) by a combination of photolithography (to define the electrodes pattern) and sputtering (gold deposition). The wafer-scale fabrication yielded 32 chips each comprising three gold electrodes $(100 \mathrm{~nm} \mathrm{Au}$ ) as well as contact pads. On-chip $\mathrm{Ag} / \mathrm{AgCl}$ reference electrodes were prepared in-house by electroplating and the individual chips were finally diced. The generated chips were characterized electrochemically and by scanning electron microscopy. The mAbs were thiolated by its incubation with Traut's reagent at a molar ratio of $1: 15$ for $1 \mathrm{hr}$ at room temperature followed by washing with $0.1 \mathrm{M}$ phosphate buffer $\mathrm{pH} 5$ to remove the unreacted reagent ${ }^{9}{ }^{10}$. Thiolated mAbs were then covalently immobilized onto the gold working electrodes of the chips by drop-casting after thoroughly cleaning the electrodes by immersing $20 \mathrm{~min}$ in a solution of $50 \mathrm{mM} \mathrm{KOH}$ and $25 \% \mathrm{H}_{2} \mathrm{O}_{2}$ followed by thorough rinsing with Milli-Q water.

Biosensor measurements

Biosensor measurements were based on Electrochemical Impedance Spectroscopy (EIS) recorded by a commercial potentiostat device (BioLogic). The faradaic current response of a routinely employed redox couple $\left(10 \mathrm{mM} \mathrm{K}_{3} \mathrm{Fe}(\mathrm{CN})_{6}\right)$ found within the measurement buffer, was monitored both by cyclic voltammetry $(\mathrm{CV})$ and EIS. The impedance spectra of the freshly cleaned electrodes were obtained prior and post antibody immobilization, with a potential amplitude of $5 \mathrm{mV}$ at a frequency range of $100 \mathrm{kHz}$ to $10 \mathrm{~Hz}$. The $\mathrm{CV}$ was collected within a potential range of $-200-600 \mathrm{mV} v \mathrm{~s}$. $\mathrm{gg} / \mathrm{AgCl}$ at a scan rate of 100 $\mathrm{mV} / \mathrm{sec}$. Purified EspB protein solutions (at the concentration of $0,1,4,10$, and $250 \mu \mathrm{g} / \mathrm{mL}$ in PBS) were incubated for $10 \mathrm{~min}$ on the working electrode and then measured by the EIS method. The specificity of the obtained signals was verified by two control experiments. A negative control that included an unrelated antigen $(2 \mu \mathrm{g} / \mathrm{ml}$ of the toxin Microcystin-LR, PubChem CID: 445434) and additionally, a purified EspB antigen $(2 \mu \mathrm{g} / \mathrm{mL}$ ) without the immobilized $\mathrm{mAb}$ (on a nonfunctionalized bare electrode). All Measurements of soluble EspB were repeated 3-6 times for each protein concentration. The charge transfer resistance $\left(R_{c t}\right)$ values were obtained by fitting the generated Nyquist plots to a Randles equivalent circuit (see page S5 below for further details). The percent change in $R_{c t}$ ratios between the biofunctionalized electrodes and varying EspB concentrations was calculated and averaged from: $\sum R_{c t}(E s p B) / R_{c t}(m A b)-1$. In order to detect whole bacterial cell suspensions, EPEC WT and $\triangle \mathrm{espB}$ mutant strains were cultured as described above (see page $\mathrm{S} 2$ ), gently centrifuged ( $500 \mathrm{xg}, 5 \mathrm{~min}$ ) and resuspended in PBS to a concentration of $3 \times 10^{7}$ cells $/ \mathrm{mL}$. Five microliter of bacteria-containing samples were incubated on the biochip electrode for $10 \mathrm{~min}$, the electrode was then rinsed and CV and EIS measurements were taken. The percent change in $R_{c t}$ ratios measured for EPEC WT and $\triangle \mathrm{espB}$ was calculated and averaged from 20 repeats (five measurements each containing four samples) for each strain. The mean of the averaged ratios and the standard error of the mean were calculated. Differences between the means were statistically significant as indicated by a t-test using an alpha level of 0.05 . In order to compare the means of $R_{c t}$ ratios of both strains, standard errors were combined in quadrature. 
Nano Differential Scanning Fluorimetry (NanoDSF)

To assess the thermal stability of $\mathrm{mAb}-\mathrm{B} 7,20 \mu \mathrm{M}$ mAb-B7 samples were loaded into UV capillaries (NanoTemper Technologies) and analyzed using the nanoDSF Prometheus NT.48. The temperature gradient was set to $1^{\circ} \mathrm{C} / \mathrm{min}$ increase between $15^{\circ} \mathrm{C}$ and $95^{\circ} \mathrm{C}$. The melting temperatures $(\mathrm{Tm})$ that was derived from protein unfolding was presented by plotting the tryptophan fluorescence at $\lambda=330 \mathrm{~nm}$ and $\lambda=350 \mathrm{~nm}$ over temperature. The melting temperatures were determined by calculating the maximum of the first derivative and the peak position (at $\mathrm{T}_{\mathrm{m}}$ ) was determined.

Electrochemical Impedance Spectroscopy (EIS) measurements

In a faradaic impedance measurement a small sinusoidal $\mathrm{AC}$ voltage probe is applied while monitoring the current response at different frequencies. The real (resistive) component of the impedance (determined by the in-phase current response) is plotted against the imaginary (capacitive) component (determined by the out-of-phase current response) with respect to frequency. Both are described by: $Z^{\prime}=R_{s}+\frac{R_{c t}}{1+\omega^{2} R_{c t}^{2} C_{d l}^{2}}$ and $Z^{\prime \prime}=\frac{R_{c t}^{2} C_{d l} \omega}{1+\omega^{2} R_{c t}^{2} C_{d l}^{2}}$, where $R_{s}$ is the solution resistance, $R_{c t}$ the charge transfer resistance, $C_{d l}$ is the double layer capacitance and $\omega$ the angular frequency, which are commonly represented in a Nyquist plot. The impedance results of the thus-obtained Nyquist plot are fitted to an equivalent circuit (Randles circuit) used to interpret the electrochemical system, as shown in the inset of Figure 7a. An increase in charge transfer resistance $\left(R_{c t}\right)$ is attributed to surface adsorption of bound biomolecules.

The equivalent circuit

The Nyquist plots generated during EIS measurements were fitted to the following Randles circuit from which $R_{c t}$ values were calculated:

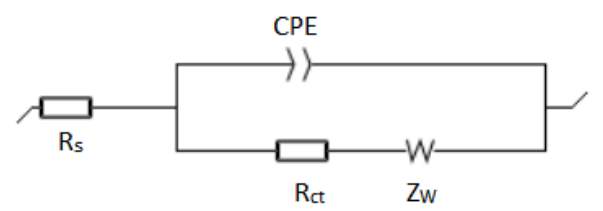
$\mathrm{R}_{\mathrm{s}}$ - solution resistance
$\mathrm{R}_{\mathrm{ct}}$ - charge transfer resistance
$\mathrm{Z}_{\mathrm{w}}$ - Warburg element

CPE - constant phase element 
FIGURES

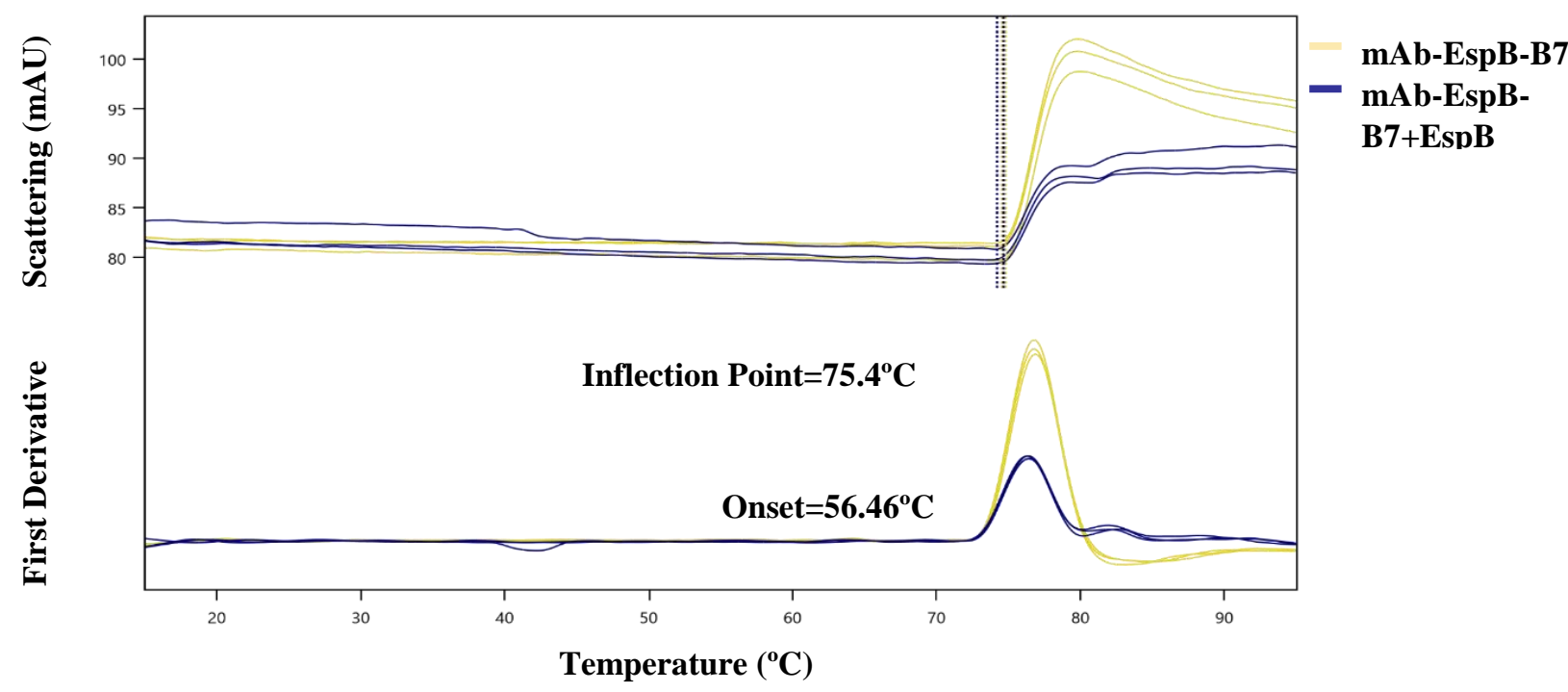

Figure S1. mAb-EspB-B7 is thermally stable. The melting temperatures $\left(\mathrm{T}_{\mathrm{m}}\right)$ of $\mathrm{mAb}-\mathrm{EspB}-\mathrm{B} 7$ alone or in combination with recombinant EspB were determined by nano Differential Scanning Fluorimetry (nanoDSF), Prometheus NT.48, NanoTemper. 
A

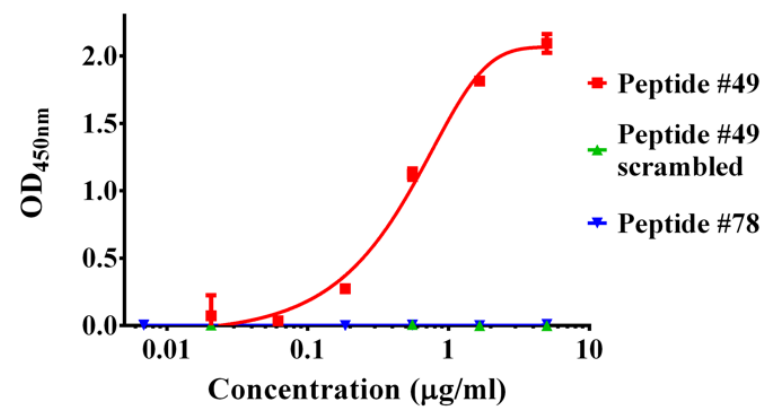

B

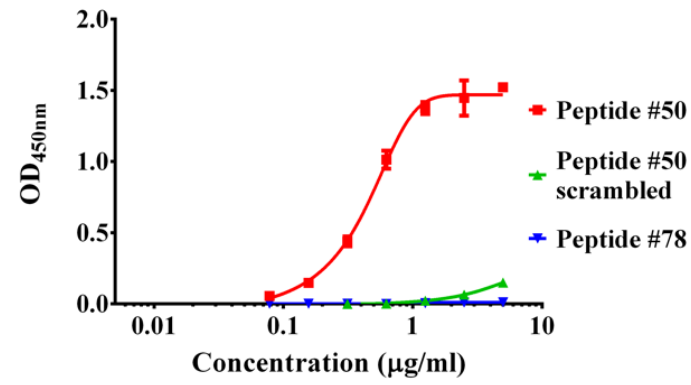

C 


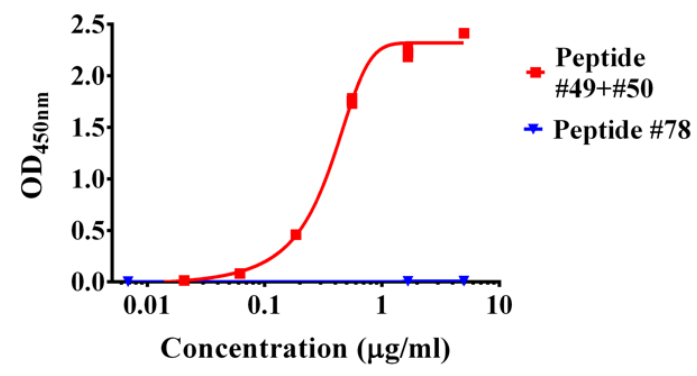

D

\begin{tabular}{|l|l|}
\hline \multicolumn{1}{|c|}{ Peptide number } & \multicolumn{1}{c|}{ Sequence } \\
\hline Peptide \#49 & CTSAQKASQVAEEAADC \\
\hline Peptide \#49 scrambled & CSSEVQAAKADTEAQAC \\
\hline Peptide \#50 & CKASQVAEEAADAAQEC \\
\hline Peptide \#50 scrambled & CDEAVAQAAAEKEAQSC \\
\hline Peptide \#49+50 & CTSAQKASQVAEEAADAAQEC \\
\hline Peptide \#78 & CTDLINRMGQAARLAGC \\
\hline
\end{tabular}

Figure S2. $\mathrm{mAb}$-EspB-B7 binding to EspB peptides. (A, B, C) mAb-EspB-B7 binding to peptide \#49 and peptide \#49 scrambled (A), peptide $\# 50$ and peptide $\# 50$ scrambled (B), or to peptide \#49+50 (C) was evaluated by ELISA. A 96 well plate was coated with the peptides before being incubated with serially diluted $\mathrm{mAb}-\mathrm{B} 7$ and detected using anti-human IgG HRP-conjugated antibody. Peptide \#78 was used as a negative control. Error bars represent +/- SD. (D) Sequences of peptides \#49, \#49 scrambled, $\# 50$, \#50 scrambled, \#49+50 and \#78. Each peptide was synthesized with the addition of cysteine residues at the $\mathrm{C}$ and $\mathrm{N}$-termini, to enable peptide cyclization.

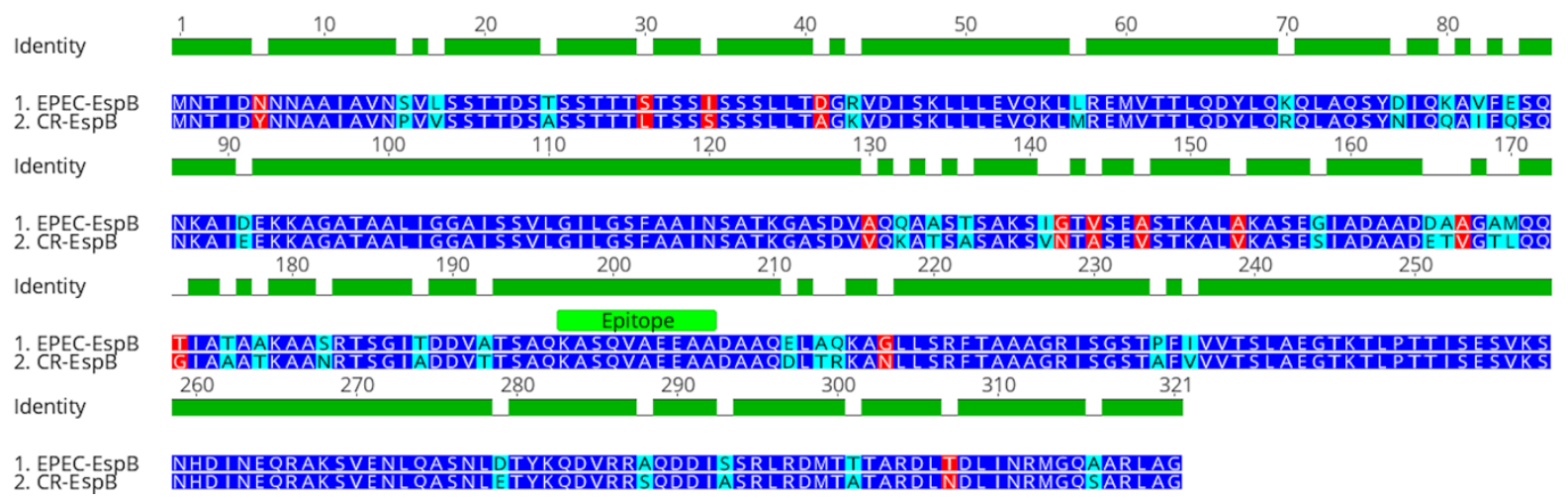


Identity

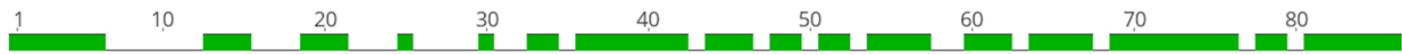

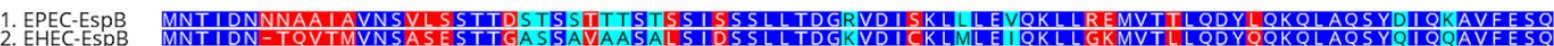
\begin{tabular}{ccccccccc} 
& 90 & 100 & 110 & 120 & 130 & 140 & 150 & 160 \\
\hline
\end{tabular}

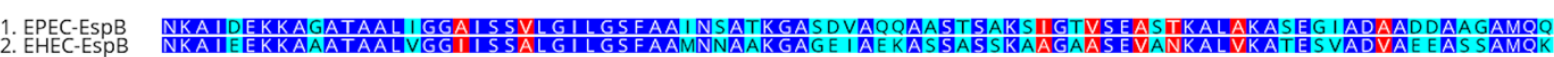
Identity

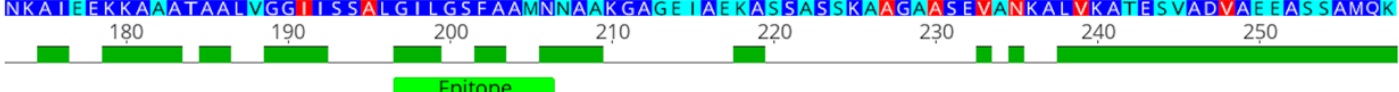
1. EPEC-ESPB TIATAAKAASRTSGITDDVATSAOKASOVAEEAADAAOELAQIKAGL LSRFTAAAGR I SIGSTPFIIVVTSLAEGTKTLPTTISESVKS Identity

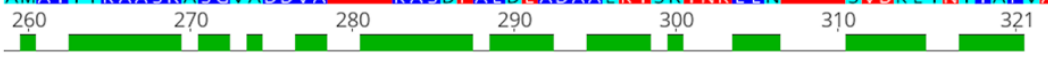

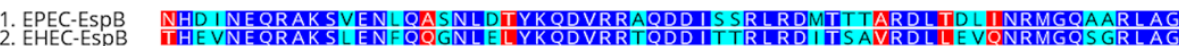

Identity

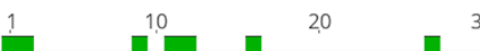

30

50

60 \begin{tabular}{rr}
70 & 80 \\
\hline
\end{tabular}

1. EPEC-EspB

Identity

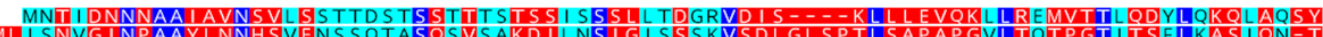

\begin{tabular}{lllllll}
90 & 100 & 110 & 130 & 130 & 150 \\
\hline
\end{tabular}

1. EPEC-EspB

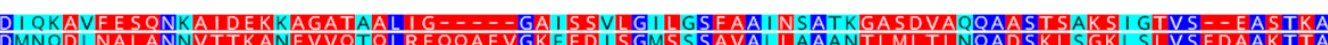

$\begin{array}{cccccccc}170 & 180 & 190 & 200 & 210 & 220 & 230 & 240\end{array}$

Identity

1. EPEC-EspB
2. Salmonella-EspB

Epitope

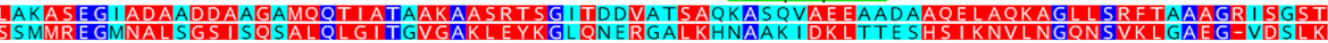

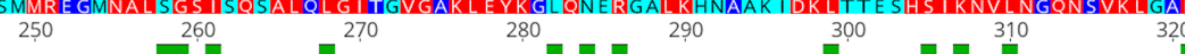

Identity

1. EPEC-EspB
2. Salmonella-EspB

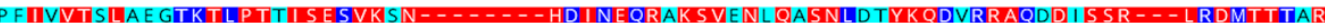

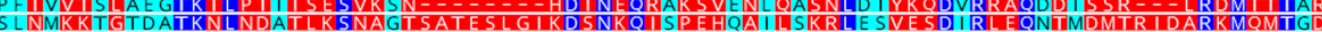

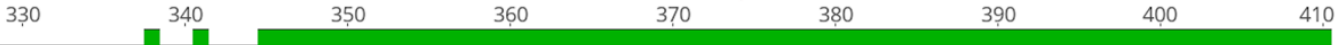

Identity

1. EPEC-EspB

Identity

DL TDL INRMMGOAARLATG

411

1. EPEC-EspB
2. Salmonella-EspB

Figure S3. mAb-EspB-B7 sequence alignment with EspB homologs in other T3SS-expressing bacteria. Amino acid sequence alignment of EspB from EPEC with C. rodentium, EHEC, or Salmonella EspB homologs. Identical, similar and nonidentical amino acids are marked in blue, cyan, and red, respectively. The mAb-EspB-B7 epitope is annotated above the amino acids that are part of the epitope. 
A
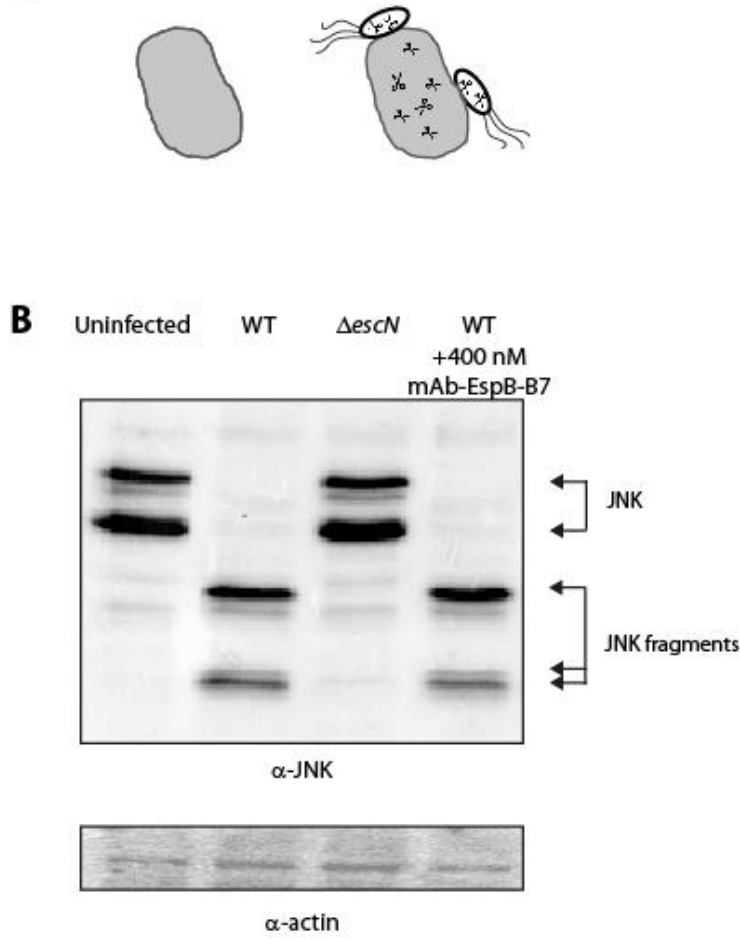

Figure S4. mAb-EspB-B7 does not inhibit EPEC translocation activity into HeLa cells. (A) Scheme of the effector translocation assay. Infection of HeLa cells with EPEC was monitored by detecting the degradation profile of JNK, a human kinase that is subjected to cleavage by the EPEC effector, NleD. (B) HeLa cells were infected with wild-type (WT) EPEC in the presence or absence of $400 \mathrm{nM}$ mAb-EspB-B7. After $3 \mathrm{hr}$, cells were washed, and host cell proteins were extracted and subjected to western blot analysis using anti-JNK and anti-actin (loading control) antibodies. JNK and its degradation fragments are indicated at the right of the gel. Degradation of JNK was evident in the WT EPEC, sample but not in the uninfected sample or in the samples infected with EPEC $\triangle e s c N$. HeLa cells infected with WT EPEC in the presence of $400 \mathrm{nM}$ mAb-EspB-B7 showed a JNK degradation profile similar to that of WT EPEC in the absence of mAb-EspB-B7.

\section{References}

1. Gauthier, A.; Puente, J. L.; Finlay, B. B., Secretin of the enteropathogenic Escherichia coli type III secretion system requires components of the type III apparatus for assembly and localization. Infect Immun 2003, 71, 3310-9.

2. Iguchi, A.; Thomson, N. R.; Ogura, Y.; Saunders, D.; Ooka, T.; Henderson, I. R.; Harris, D.; Asadulghani, M.; Kurokawa, K.; Dean, P.; Kenny, B.; Quail, M. A.; Thurston, S.; Dougan, G.; Hayashi, T.; Parkhill, J.; Frankel, G., Complete genome sequence and comparative genome analysis of enteropathogenic Escherichia coli O127:H6 strain E2348/69. J Bacteriol 2009, 191, 347-54.

3. Luo, W.; Donnenberg, M. S., Analysis of the function of enteropathogenic Escherichia coli EspB by random mutagenesis. Infect Immun 2006, 74, 810-20.

4. $\quad$ Frankel, G.; Phillips, A. D.; Rosenshine, I.; Dougan, G.; Kaper, J. B.; Knutton, S., Enteropathogenic and enterohaemorrhagic Escherichia coli: more subversive elements. Mol Microbiol 1998, 30, 911-21. 
5. Deng, W.; Li, Y.; Hardwidge, P. R.; Frey, E. A.; Pfuetzner, R. A.; Lee, S.; Gruenheid, S.; Strynakda, N. C.; Puente, J. L.; Finlay, B. B., Regulation of type III secretion hierarchy of translocators and effectors in attaching and effacing bacterial pathogens. Infect Immun 2005, 73, 2135-46.

6. Mills, S. D.; Finlay, B. B., Comparison of Salmonella typhi and Salmonella typhimurium invasion, intracellular growth and localization in cultured human epithelial cells. Microb Pathog 1994, 17, 409-23.

7. Gibson, D. G.; Young, L.; Chuang, R. Y.; Venter, J. C.; Hutchison, C. A., 3rd; Smith, H. O., Enzymatic assembly of DNA molecules up to several hundred kilobases. Nat Methods 2009, 6, 343-5.

8. Vaisman-Mentesh, A.; Rosenstein, S.; Yavzori, M.; Dror, Y.; Fudim, E.; Ungar, B.; Kopylov, U.; Picard, O.; Kigel, A.; Ben-Horin, S.; Benhar, I.; Wine, Y., Molecular Landscape of Anti-Drug Antibodies Reveals the Mechanism of the Immune Response Following Treatment With TNFalpha Antagonists. Front Immunol 2019, $10,2921$.

9. Chatrathi, M. P.; Wang, J.; Collins, G. E., Sandwich electrochemical immunoassay for the detection of Staphylococcal enterotoxin B based on immobilized thiolated antibodies. Biosens Bioelectron 2007, 22, 29322938.

10. Fowler, J. M.; Stuart, M. C.; Wong, D. K. Y., Self-assembled layer of thiolated protein G as an immunosensor scaffold. Analytical Chemistry 2007, 79, 350-354. 